\title{
OPEN Thermophysiological comfort of zinc oxide nanoparticles coated woven fabrics
}

\begin{abstract}
Muhammad Tayyab Noman ${ }^{1 凶}$, Michal Petru ${ }^{1}$, Nesrine Amor ${ }^{2}$ \& Petr Louda ${ }^{3}$
This study investigates physicochemical impact of ultrasonic irradiations on surface topography of woven fabrics. In a simultaneous in-situ sonochemical method, the synthesis and coating of zinc oxide nanoparticles (ZnO NPs) on woven textiles were successfully achieved. Different instruments i.e. Alambeta, moisture management tester, air permeability tester and permetester were utilised during experimentation for thermal evaluation, moisture transportation and air permeation. The results regarding thermophysiological comfort of $\mathrm{ZnO}$ coated fabrics were evaluated on the basis of thickness and ZnO NPs coated amount on fabrics. In addition, the achieved results depict the impact of sonication (pressure gradient) on surface roughness of cotton and polyester. The coating of ZnO NPs on fabrics, crystal phase identification, surface topography and fluctuations in surface roughness were estimated by inductively coupled plasma atomic emission spectroscopy (ICP-AES), X-ray Diffractometry (XRD), ultrahigh-resolution scanning electron microscopy (UHR-SEM) and energy dispersive X-ray (EDX). Moreover, thermophysiological properties i.e. thermal conductivity, absolute evaporative resistance, thermal absorptivity, air permeability, overall moisture management capacity and relative water vapour permeability of untreated and $\mathrm{ZnO}$ treated samples were evaluated by standard test methods.
\end{abstract}

In textiles, thermophysiological comfort is considered as most demanding and desirable characteristics that is achieved by maintaining heat and mass transfer phenomena. Comfort helps the customer to choose a suitable fabric for cold as well as for hot weather. From experimental point of view, thermophysiological and sensorial comfort are two most important and significant categories of clothing comfort among other categories. In recent years, many researchers worked with different textiles for thermophysiological comfort and reported interesting results but their results were based on thermophysiological properties of plain non-coated fabrics (nanostructures were not applied on samples) ${ }^{1-3}$. Azeem et al. studied thermophysiological properties of multifilament polyester non-coated fabric and claimed that nanofilament fabric possess remarkably higher thermal conductivity than coolmax and pure cotton. Their work composed of non-coated samples for all substrates. A lower value of thermal absorptivity induced warm feeling and a higher value gives cool feeling in nanofilament polyester fabric ${ }^{4}$. In another study, Angelova et al. proposed a comprehensive comfort analysis of woven and non-woven fabrics made of cotton, polyester and polyamide. Their work was also composed of non-coated samples for all kind of textile substrates. They reported that thermophysiological comfort is significantly affected by number of fabric layers, bulk density, fabric thickness and porosity of used materials ${ }^{5}$. Mishra et al. worked with comfort evaluation of 3D spacer knitted fabrics segregated into two major groups for a comprehensive analysis. They chose blended fabrics for both groups i.e. polyester/polypropylene and polyester/polypropylene/lycra with different compositions. They found that water vapour permeability is highly affected by the type of textile materials. In addition, air permeability depends on fabric density and fabric thickness ${ }^{6}$. However, there are very limited studies based on nanomaterials coated textiles and their thermophysiological comfort evaluation ${ }^{7,8}$. In previous studies, thermophysiological evaluation of nano $\mathrm{TiO}_{2}$ coated fabrics were carried out and interesting results were obtained ${ }^{9,10}$.

$\mathrm{ZnO}$ is a fascinating material with exceptional physicochemical properties. These properties (thermal conductivity, high electron mobility, high exciton binding energy, wide band gap) allow $\mathrm{ZnO}$ to function under infinite range of applications ${ }^{11}$. Researchers have reported the synthesis and deposition of $\mathrm{ZnO}$ nanostructures

${ }^{1}$ Department of Machinery Construction, Institute for Nanomaterials, Advanced Technologies and Innovation (CXI), Technical University of Liberec, 461 17, Studentská 1402/2 Liberec 1, Czech Republic. ${ }^{2}$ Acoustic Signal Analysis and Processing Group, Faculty of Mechatronics, Informatics and Interdisciplinary Studies, Technical University of Liberec, 461 17, Studentská 1402/2 Liberec 1, Czech Republic. ${ }^{3}$ Department of Material Science, Faculty of Mechanical Engineering, Technical University of Liberec, 461 17, Studentská 1402/2 Liberec 1, Czech Republic. ${ }^{凶}$ email: tayyab_noman411@yahoo.com 


\begin{tabular}{|l|l|l|l|l|l|l|}
\hline Sample ID & $\begin{array}{l}\text { Composition } \\
(\mathbf{1 0 0})\end{array}$ & Yarn count $($ tex) & $\begin{array}{l}\text { Yarn density } \\
\text { (threads/inch) }\end{array}$ & $\begin{array}{l}\text { ZnO NPs coated } \\
\text { amount }(\mathbf{p p m})\end{array}$ & GSM $\left(\mathbf{g ~ m}^{-2}\right)$ & Thickness $(\mathbf{m m})$ \\
\hline $\mathrm{F}_{1}$ & Cotton & 22 & 74 & - & 110 & 0.25 \\
\hline $\mathrm{F}_{2}$ & Cotton & 22 & 74 & 581 & 115 & 0.31 \\
\hline $\mathrm{F}_{3}$ & Cotton & 22 & 74 & 1090 & 118 & 0.38 \\
\hline $\mathrm{F}_{4}$ & Cotton & 28 & 52 & - & 224 & 0.66 \\
\hline $\mathrm{F}_{5}$ & Cotton & 28 & 52 & 598 & 229 & 0.72 \\
\hline $\mathrm{F}_{6}$ & Cotton & 28 & 52 & 1110 & 233 & 0.77 \\
\hline $\mathrm{F}_{7}$ & Polyester & 20 & 80 & - & 118 & 0.32 \\
\hline $\mathrm{F}_{8}$ & Polyester & 20 & 80 & 493 & 124 & 0.36 \\
\hline $\mathrm{F}_{9}$ & Polyester & 20 & 80 & 1032 & 128 & 0.41 \\
\hline $\mathrm{F}_{10}$ & Polyester & 27 & 58 & - & 230 & 0.66 \\
\hline $\mathrm{F}_{11}$ & Polyester & 27 & 58 & 583 & 234 & 0.78 \\
\hline $\mathrm{F}_{12}$ & Polyester & 27 & 58 & 1096 & 238 & 0.84 \\
\hline
\end{tabular}

Table 1. The detail of important parameters of samples and ICP-AES results.

by sol-gel, hydrothermal and chemical vapours deposition methods on textiles and other substrates for photocatalytic, photovoltaic and functional applications $\mathrm{s}^{12-20}$. These approaches are time consuming and most of them involve two step deposition of $\mathrm{ZnO}$. However, the process of sonication (utilization of ultrasonic energy) for the fabrication and incorporation of a variety of nanostructures (organic, inorganic, metallic, non-metallic etc.) on textiles has become facile, economical and environmentally friendly method ${ }^{21}$. This approach works through the principle of acoustic cavitation i.e. generation of unstable bubbles in liquids that violently collapse and increase temperature and pressure up to $5000 \mathrm{~K}$ and $20 \mathrm{MPa}$ with cooling rate of $10^{10} \mathrm{~K} \mathrm{~s}^{-1}$ respectively ${ }^{22}$.

The literature regarding one step coating of $\mathrm{ZnO}$ NPs on textiles for the evaluation of comfort properties is extremely rare and to the best of knowledge, the only work on thermophysiological properties of $\mathrm{ZnO}$ coated cotton was reported by Dal et al. ${ }^{23}$. They studied comfort properties of $\mathrm{ZnO}$ coated twill cotton to a limited level. In a recent work, $\mathrm{ZnO}$ NPs with pure wurtzite crystal structure were fabricated and coated on cotton fabric by sonication under optimised conditions ${ }^{24}$. However, comfort properties were not discussed. Based on above discussion, it was concluded that a simultaneous synthesis and coating of $\mathrm{ZnO}$ NPs on textiles (single step) via sonication is a novel approach for the investigation of thermophysiological comfort evaluation. Therefore, in this study, a correlation between the deposited amount of $\mathrm{ZnO}$ NPs on different textiles via sonication and comfort properties was drawn. This study explicitly demonstrates and elaborates the effects of ultrasonic irradiations as a potential tool to deposit ZnO NPs on cotton and polyester fabrics for thermophysiological comfort. The approach delineates here thereby opens up a new avenue towards other textile substrates and coating materials.

\section{Materials and methods}

Materials. Woven fabrics (plain weave) made of $100 \%$ pure cotton and polyester threads used in this work. All other chemicals i.e. $\mathrm{ZnCl}_{2}, \mathrm{NaOH}$ and $\mathrm{C}_{2} \mathrm{H}_{5} \mathrm{OH}$ were used as received from Sigma Aldrich for the synthesis ZnO NPs.

Physical testing. Fabric samples were conditioned before testing at $20 \pm 2{ }^{\circ} \mathrm{C}$ temperature and $65 \pm 2 \%$ relative humidity (standard conditions) for $24 \mathrm{~h}$ according to ASTM D 1776-16 standard test procedure. ASTM D 3776 was used to calculate gram per square meter (GSM) or fabric mass. Fabric thickness was determined according to standard test method ASTM D 1777-96 (2019). In addition, Table 1 shows the detail of necessary parameters of all coded samples.

Synthesis and coating of ZnO NPs. ZnO NPs were synthesized and coated on both fabric samples in a single step according to the procedure as described in previous investigation ${ }^{22}$. In a typical method, samples were immersed in a beaker and varying amount of $\mathrm{ZnCl}_{2}$ was added. Distilled water was added into the beaker to adjust $100 \mathrm{~mL}$ of total volume. The solution was sonicated for $5 \mathrm{~min}$ to prepare homogeneity. The granules of $\mathrm{NaOH}$ were added to solution in order to complete reaction. The running solution was sonicated for $1 \mathrm{~h}$ with ultrasonic probe homogeniser under optimised conditions. After sonication, samples were removed from their respective solution, squeezed on padder at a pressure of $3 \mathrm{kN}$ with $1 \mathrm{~m} \mathrm{~min}^{-1}$ velocity and dried at $60{ }^{\circ} \mathrm{C}$ in an oven. The remaining solution of each sample was centrifuged at $4000 \mathrm{rpm}$ to separate the flocculates of $\mathrm{ZnO}$ NPs from liquid for $\mathrm{XRD}$ analysis. The collected $\mathrm{ZnO}$ powders were dried at $80^{\circ} \mathrm{C}$ for $1 \mathrm{~h}$ in oven to eliminate impurities and excess amount of moisture. A schematic explanation of the proposed method is presented in Fig. 1. ZnO NPs were characterised for crystal phase identification, morphology, topography and purity. SEM (UHR-SEM Zeiss Ultra Plus) was utilised to analyse morphological and topographical changes for all treated and untreated samples. EDX spectrophotometer was used to detect composition of elements and percentage amount of deposited materials. XRD analysis was performed for crystal phase identification. XRD patterns were matched with standard patterns of International Centre for Diffraction Data (ICDD) Powder Diffraction File (PDF: 89-7102). The coated amount of ZnO NPs on sample surface was calculated by ICP-AES analysis. 


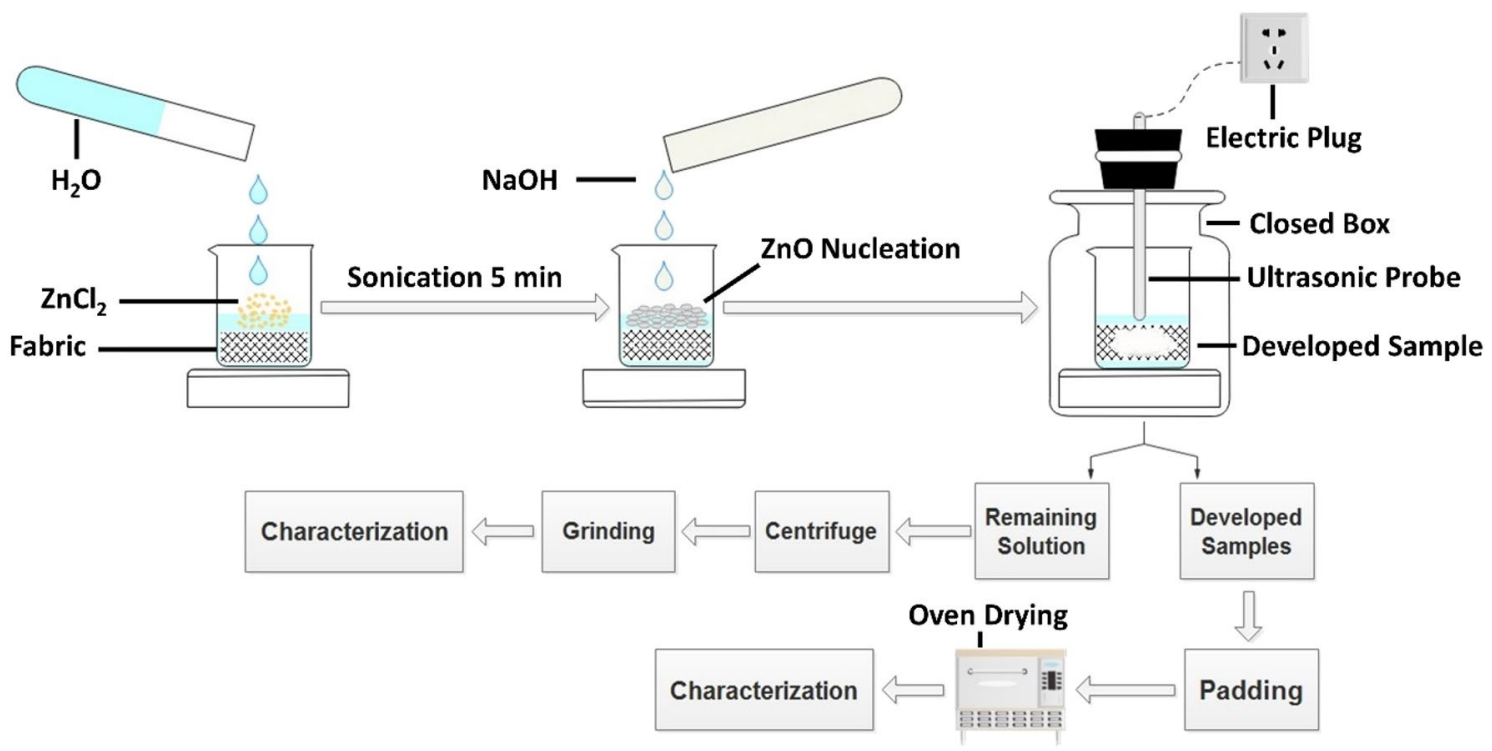

Figure 1. Graphical representation of proposed system and experimental study.

Thermophysiological comfort properties. Alambeta instrument (developed by Sensora) was utilised for the evaluation of thermal conductivity coefficient $(\lambda)\left(\mathrm{Wm}^{-1} \mathrm{~K}^{-1}\right)$ and thermal absorptivity (b) (Ws $\mathrm{Ws}^{1 / 2}$ $\left.\mathrm{m}^{-2} \mathrm{~K}^{-1}\right)$. It also evaluates fabric thickness ${ }^{9}$. Alambeta calculates net amount of heat passes from a material having area of $1 \mathrm{~m}^{2}$ within $1 \mathrm{~s}$ and covers a distance of $1 \mathrm{~m}$ with temperature difference of $1 \mathrm{~K}$. The coefficient of thermal conductivity is estimated by given equation.

$$
\lambda=\frac{Q \times h}{A \times t \times \Delta T}
$$

In Eq. (1), $Q$ shows net amount of heat flow, $h$ represents thickness, $A$ is cross-sectional area, $t$ is total time taken and $\Delta T$ shows temperature gradient respectively 9 .

Thermal absorptivity (b) is the measure of warm-cool feeling. Higher thermal absorptivity means cool feeling when body gets in touch with fabric and vice versa. The following equation calculates thermal absorptivity.

$$
b=\sqrt{\rho \times \lambda \times c}
$$

Permetester was utilised for relative water vapour permeability (RWVP) [\%] and absolute evaporative resistance $\left(\mathrm{R}_{\mathrm{et}}\right)\left(\mathrm{m}^{2} \mathrm{PaW}^{-1}\right)$. ISO 11092-2014 standard method was used to measure the values of RWVP and $\mathrm{R}_{\mathrm{et}}$. Both parameters are useful in the evaluation of net water vapours transport capacity ${ }^{9}$. Equation (3) is used for the calculation of RWVP.

$$
R W V P=\frac{q_{f}}{q_{o}} \times 100
$$

In above equation, $q_{f}$ and $q_{o}$ represent heat loss with and without fabric sample respectively.

SDL ATLAS air permeability tester was utilised to determine air permeability by ISO 9237-1995 standard method. For this test, air pressure was set at $100 \mathrm{~Pa}^{9}$. Overall moisture management capacity (OMMC) is another vital attribute of thermophysiological comfort. Moisture management tester (MMT) was utilised for the measurement of OMMC. AATCC 195-2009 method was performed to determine OMMC. This property calculates the ability of textiles to deal with moisture ${ }^{9}$.

Statistical analysis. The obtained results for all comfort related properties subjected to ZnO NPs coating by sonication method were statistically assessed by regression.

Reusability. In order to confirm reusability and sequential performance, the durability of all treated samples was evaluated against washing by standard method ISO $105 \mathrm{C} 06$. This method is considered as a direct approach to determine durability against washing. In this process, one cycle consists $4 \mathrm{~g} \mathrm{~L}^{-1}$ detergent that takes $45 \mathrm{~min}$ to complete the cycle at $50{ }^{\circ} \mathrm{C}$. After samples removal, $\mathrm{Zn}^{2+}$ ions were calculated by ICP-AES. The study was repeated for five consecutive cycles.

\section{Results and discussions}

SEM and EDX analysis. The results regarding morphology and surface topography of all coded samples are illustrated in Fig. 2. SEM images were carried out at $5.0 \mathrm{k}$ and $10.0 \mathrm{k}$ magnifications for cotton samples $\left[\mathrm{F}_{1}\right.$ (untreated), $\mathrm{F}_{3}$ (treated)] and polyester samples $\left[\mathrm{F}_{10}\right.$ (untreated), $\mathrm{F}_{12}$ (treated)]. A smooth and very clean surface 


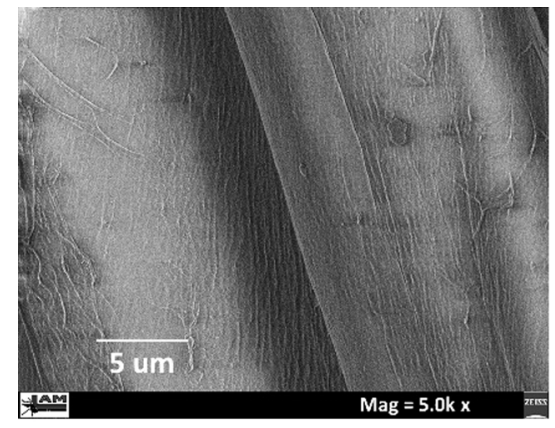

(a)

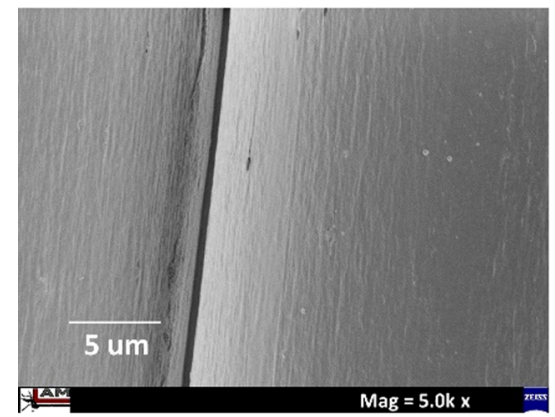

(d)

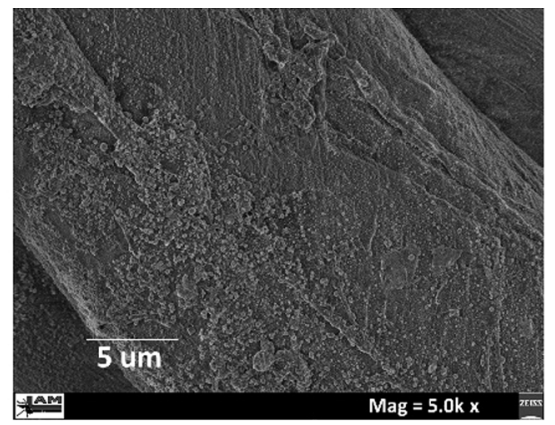

(b)

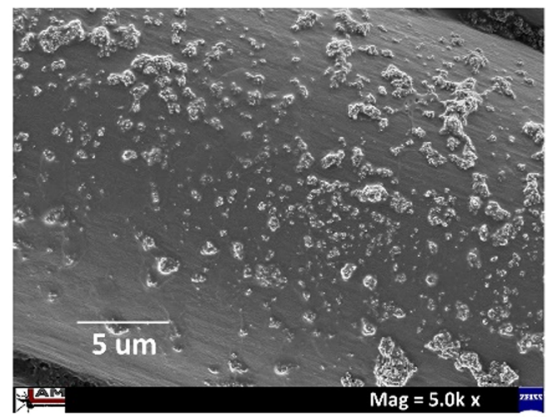

(e)

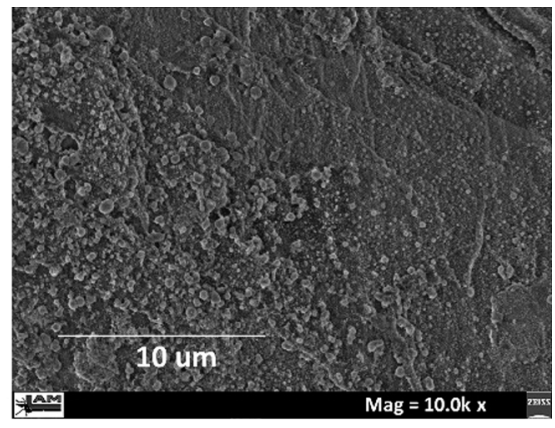

(c)

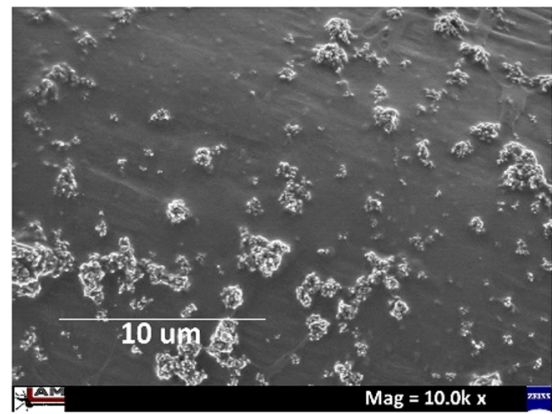

(f)

Figure 2. SEM images (a) untreated $(\mathbf{b})$ sample $F_{3}(\mathbf{c})$ sample $F_{3}$ with higher magnification of cotton fabric and (d) untreated, (e) sample $\mathrm{F}_{12}$, (f) sample $\mathrm{F}_{12}$ with higher magnification of polyester fabric.

of untreated sample of both substrates can be observed in Fig. 2a,d. Higher magnification was taken to visually guess estimated quantity (higher deposition or lower deposition) of ZnO NPs on treated fabrics. A homogenous distribution with quasi-spherical shape of ZnO NPs was detected for cotton whereas aggregation of particles was observed for polyester samples as depicted in Fig. 2b,c,e,f respectively. The impact of sonication was dominantly appeared in case of cotton as the surface was fully covered with $\mathrm{ZnO}$ NPs. However, the effects of sonication on polyester were appreciable and also acceptable.

Furthermore, EDX analysis was performed for the detection of elemental composition and weight percentage. The EDX results for sample $\mathrm{F}_{1}, \mathrm{~F}_{3}, \mathrm{~F}_{10}$ and $\mathrm{F}_{12}$ are presented in Fig. 3. EDX spectrum for samples $\mathrm{F}_{3}$ and $\mathrm{F}_{12}$ confirmed the existence of $\mathrm{ZnO}$ NPs on both fabrics as shown in (Fig. 3b,d). Though, Zn elemental peak was not found for untreated samples of cotton and polyester i.e. $\mathrm{F}_{1}$ (Fig. 3a) and $\mathrm{F}_{10}$ (Fig. 3c). In addition, EDX results confirm that the deposited amount of $\mathrm{ZnO}$ NPs was higher in cotton samples as compared to polyester. This happened due to different adsorption desorption phenomenon for cotton and polyester substrates. Due to ultrasonic energy, the surface roughness of cotton was higher as compared to polyester that ultimately results in more deposition of $\mathrm{ZnO}$ on cotton than polyester. The EDX results are in good agreement with SEM results as both techniques confirmed the excellent impact of sonication for cotton and good impact for polyester.

XRD analysis. XRD is a standard method used for identification of lattice structure and phase purity of a material. XRD results for samples $\left(F_{6}\right.$ and $\left.F_{12}\right)$ confirmed wurtzite crystal structure of $\mathrm{ZnO}$ on both fabrics. The patterns show that all peaks matched with ICDD file (PDF: 89-7102). The highest peak appeared at $2 \theta=36.2^{\circ}$ is the characteristic peak of wurtzite that follows [101] plane reflection as illustrated in Fig. 4 . In addition, a series of crystalline peaks at $2 \theta=31.7^{\circ}, 34.4^{\circ}, 47.5^{\circ}, 56.6^{\circ}, 62.8^{\circ}$ and $67.9^{\circ}$ follow [100], [002], [102], [110], [103] and [112] planes respectively. Moreover, any phase other than $\mathrm{ZnO}$ called impurities i.e. $\mathrm{Zn}(\mathrm{OH})_{2}$ were not found.

ICP-AES analysis. ICP-AES analysis confirmed the presence of ZnO NPs on both fabric samples. Though, $\mathrm{ZnO}$ was not present on untreated samples. Furthermore, for deposited amount of $\mathrm{ZnO}$ NPs on both substrates, elemental $\mathrm{Zn}$ peak was counted and results were presented in Table 1.

Thermophysiological comfort analysis. The overall results of thermophysiological analysis of all samples with varied quantity of $\mathrm{ZnO}$ NPs are presented in Table 2 and discussed one by one here. This discussion is a description that comfort is a function of fabric thickness, $\mathrm{ZnO}$ NPs coated amount on fabric and ultrasonic irradiation time. In addition, regression statistics was performed to estimate influential tendency of selected variables on achieved responses.

Thermal conductivity. Thermal conductivity is a significant and important approach to evaluate thermal comfort of any textiles. Thermal conductivity results are described in Fig. 5. Typically, higher thermal conductivity 

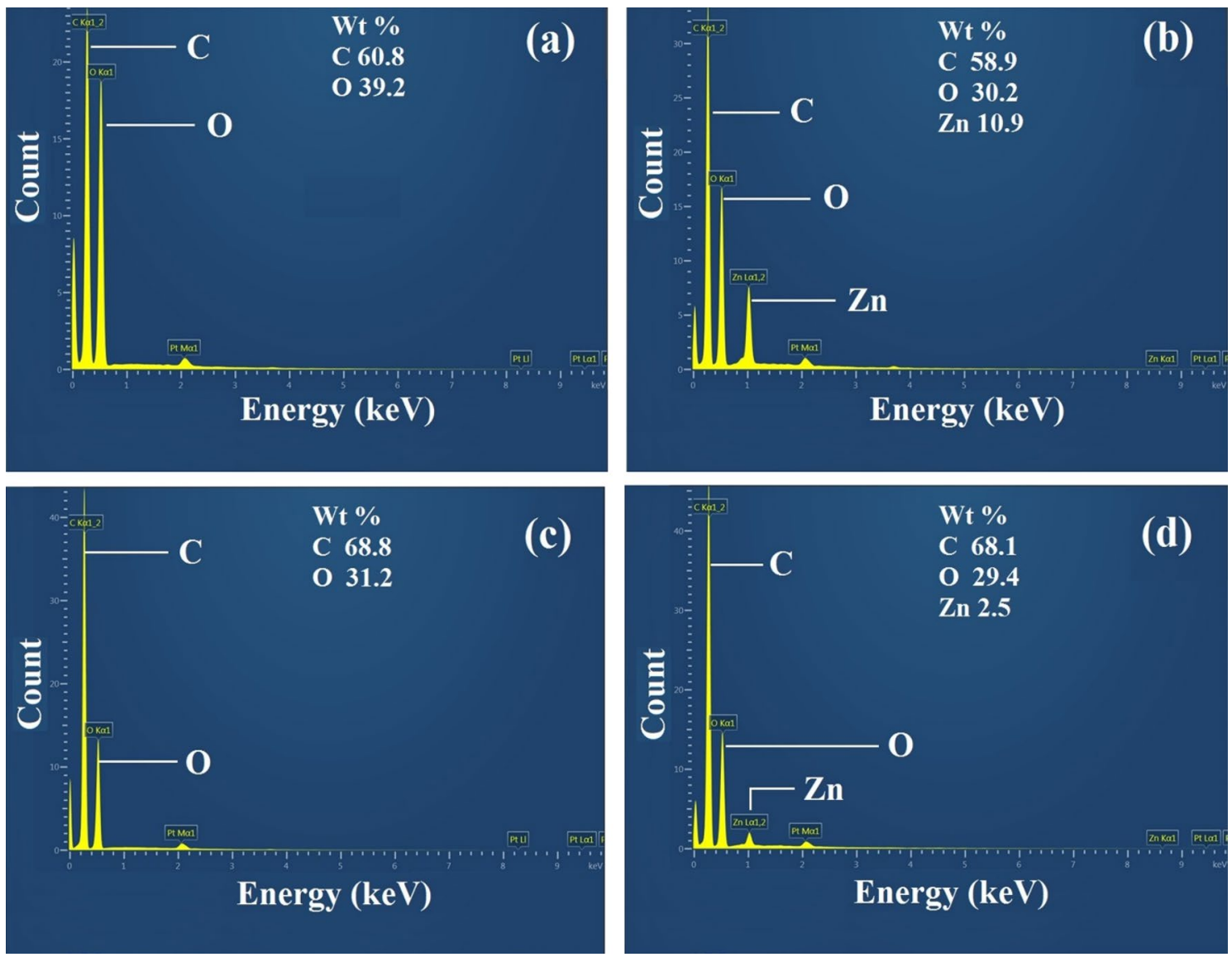

Figure 3. EDX spectra of cotton, sample $F_{1}(\mathbf{a})$, sample $F_{3}(\mathbf{b})$, and polyester, sample $F_{10}(\mathbf{c})$, sample $F_{12}(\mathbf{d})$ respectively.

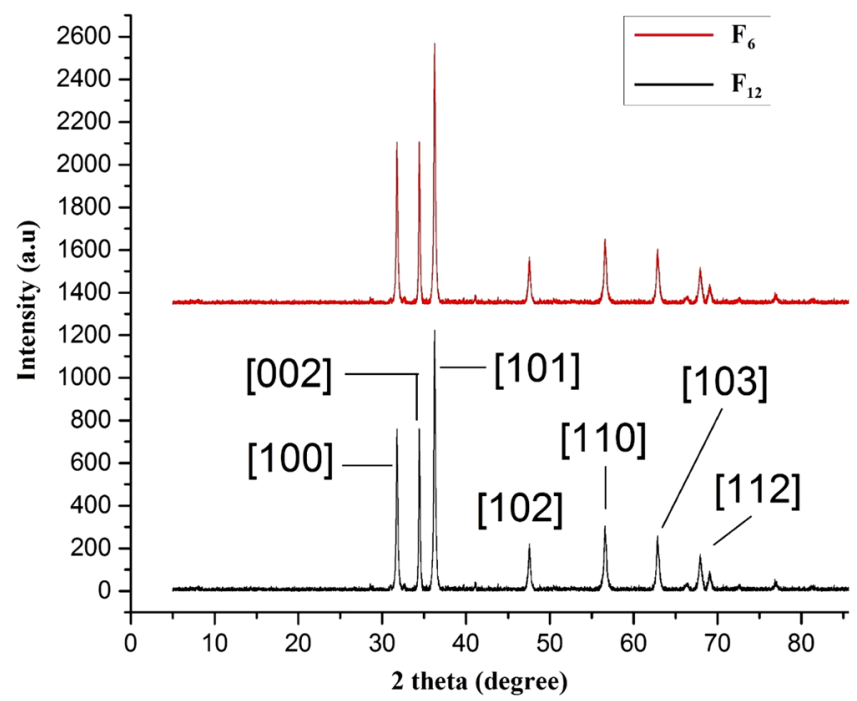

Figure 4. $\mathrm{XRD}$ results for samples $\mathrm{F}_{6}$ and $\mathrm{F}_{12}$.

means more heat is transmitted from skin to fabric and ultimately generates cool feeling to body. This is an ideal situation for hot climate specifically in summer where thermal conductivity makes the process of heat transfer easy. The results were higher for all treated samples of cotton $\left(\mathrm{F}_{2}, \mathrm{~F}_{3}, \mathrm{~F}_{5}, \mathrm{~F}_{6}\right)$ and polyester $\left(\mathrm{F}_{8}, \mathrm{~F}_{9}, \mathrm{~F}_{11}, \mathrm{~F}_{12}\right)$ than untreated ones i.e. $\mathrm{F}_{1}, \mathrm{~F}_{4}$ for cotton and $\mathrm{F}_{7}, \mathrm{~F}_{10}$ for polyester (Fig. $5 \mathrm{a}$ ). The results depict that $\mathrm{ZnO}$ coating on fabrics by sonication impart positive effects on porosity by covering the pores on fabric surface. ZnO NPs coating on both fabrics covered many empty spaces on fabric surface and reduced air entrapped inside fibre volume, and 


\begin{tabular}{|c|c|c|c|c|c|c|}
\hline Sample ID & $\begin{array}{l}\text { Thermal conductivity }(\lambda) \\
\left(\mathrm{Wm}^{-1} \mathbf{K}^{-1}\right)\end{array}$ & $\begin{array}{l}\text { Thermal absorptivity (b) } \\
\left(\mathrm{Ws}^{1 / 2} \mathrm{~m}^{-2} \mathrm{~K}^{-1}\right)\end{array}$ & RWVP (\%) & $\begin{array}{l}\text { Absolute evaporative resistance } \\
\left(\mathbf{R}_{\mathrm{et}}\right)\left(\mathrm{m}^{2} \mathrm{pa} \mathrm{W}^{-1}\right)\end{array}$ & Air permeability $\left(\mathrm{m}^{2} \mathrm{~s}^{-1}\right)$ & OMMC \\
\hline $\mathrm{F}_{1}$ & 34.4 & 160 & 75.1 & 1.9 & 467 & 0.4512 \\
\hline $\mathrm{F}_{2}$ & 38.2 & 192 & 79.3 & 1.2 & 228 & 0.6241 \\
\hline $\mathrm{F}_{3}$ & 43.4 & 201 & 82.7 & 0.8 & 71 & 0.8104 \\
\hline $\mathrm{F}_{4}$ & 49.6 & 177 & 50.9 & 4.1 & 263 & 0.5021 \\
\hline $\mathrm{F}_{5}$ & 52.4 & 198 & 57.2 & 3.3 & 125 & 0.7132 \\
\hline $\mathrm{F}_{6}$ & 56.1 & 223 & 62.5 & 2.4 & 28 & 0.8954 \\
\hline $\mathrm{F}_{7}$ & 38.5 & 179 & 67.3 & 2.5 & 1189 & 0.3652 \\
\hline $\mathrm{F}_{8}$ & 42.7 & 191 & 71.8 & 1.9 & 882 & 0.7568 \\
\hline $\mathrm{F}_{9}$ & 47.3 & 200 & 76.1 & 1.3 & 624 & 0.8147 \\
\hline $\mathrm{F}_{10}$ & 48.2 & 186 & 47.5 & 5.3 & 712 & 0.3054 \\
\hline $\mathrm{F}_{11}$ & 53.7 & 199 & 56.2 & 3.6 & 465 & 0.4789 \\
\hline $\mathrm{F}_{12}$ & 59.2 & 219 & 68.4 & 1.7 & 341 & 0.7631 \\
\hline
\end{tabular}

Table 2. Thermophysiological properties of $\mathrm{ZnO}$ NPs coated fabrics.

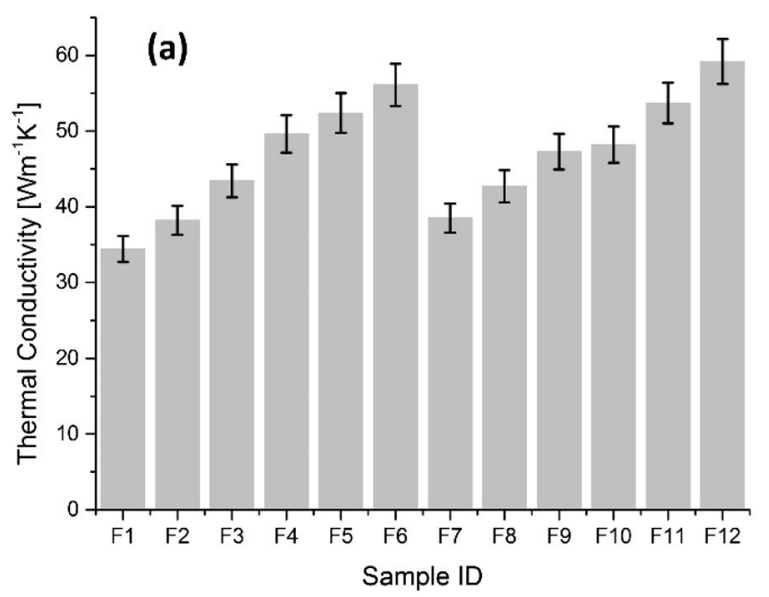

(b)

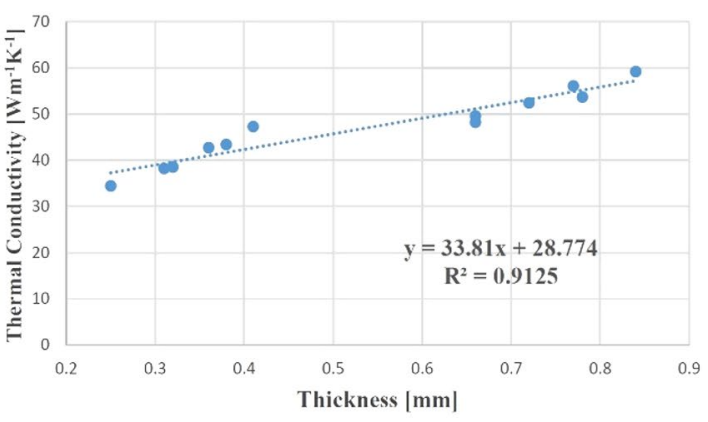

Figure 5. (a) Thermal conductivity of cotton samples $\left(\mathrm{F}_{1}-\mathrm{F}_{6}\right)$ and polyester samples $\left(\mathrm{F}_{7}-\mathrm{F}_{12}\right)$, and (b) thermal conductivity as a function of thickness.

increased thermal conductivity. Moreover, higher $\mathrm{ZnO}$ NPs deposition increased fabric thickness and reduced the air portion in treated samples and eventually provided higher thermal conductivity. The observed results are in agreement with the findings of Dalbasi and Kayseri ${ }^{25}$.

Figure $5 b$ explains the results of thermal conductivity as a function of thickness. For a better understanding, a typical point is provided that thickness itself is a function of $\mathrm{ZnO}$ NPs coated amount on fabrics that means thermophysiological properties are directly related to deposited amount of $\mathrm{ZnO}$ NPs on fabric. Therefore, comfort properties with a variation in thickness are elaborated and discussed. The trendline shows increasing tendency for thermal conductivity as thickness increased. Regression equation and $\mathrm{R}^{2}$ coefficient statically explain thermal conductivity dependency on sample thickness. A strong positive linear relationship and a strong dependency trend between fabric thickness and thermal conductivity was observed. Therefore, the developed products are a perfect option for summer wear. The results of thermal conductivity of ZnO NPs deposited woven fabrics (cotton, polyester) were slightly higher than $\mathrm{TiO}_{2} \mathrm{NPs}$ deposited woven fabrics as reported in previous investigation .

Thermal absorptivity. Another important variable and a subject of great interest is thermal absorptivity in order to estimate warm-cool feeling. In general, lower thermal absorptivity means warm feeling and vice versa when fabric gets in touch with skin. The results of thermal absorptivity of all samples are shown in Fig. 6a. The results were higher for all treated samples of cotton $\left(\mathrm{F}_{2}, \mathrm{~F}_{3}, \mathrm{~F}_{5}, \mathrm{~F}_{6}\right)$ and polyester $\left(\mathrm{F}_{8}, \mathrm{~F}_{9}, \mathrm{~F}_{11}, \mathrm{~F}_{12}\right)$ than untreated samples i.e. $\mathrm{F}_{1}, \mathrm{~F}_{4}$ for cotton and $\mathrm{F}_{7}, \mathrm{~F}_{10}$ for polyester. The results showed that treated samples provide cool feeling. These results are reasonable as ZnO NPs coating on fabrics eliminated air gap among skin and fabric and increased total contact area. Therefore, higher values of thermal absorptivity were achieved as a result. The achieved results showed positive and significant impact of $\mathrm{ZnO}$ NPs coating on thermal absorptivity.

Figure $6 \mathrm{~b}$ explains the results of thermal absorptivity as a function of thickness. The trendline shows an increased tendency of thermal absorptivity with an increase in fabric thickness. Regression equation and $\mathrm{R}^{2}$ coefficient statically explain thermal absorptivity dependency on sample thickness. A positive linear relationship with a dependency trend was observed between thermal absorptivity and thickness of fabrics. The achieved results are in agreement with the findings of Arumugam et al. $^{26}$. 
(a)

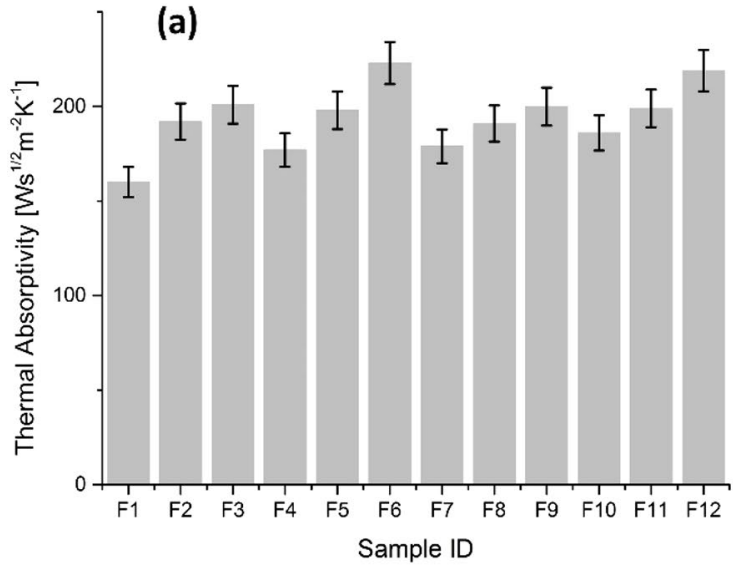

(b)

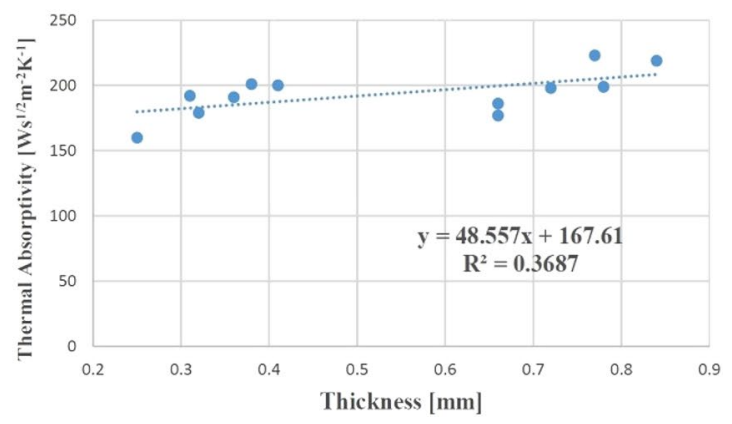

Figure 6. (a) Thermal absorptivity of cotton samples $\left(\mathrm{F}_{1}-\mathrm{F}_{6}\right)$ and polyester samples $\left(\mathrm{F}_{7}-\mathrm{F}_{12}\right)$, and (b) thermal absorptivity as a function of thickness.

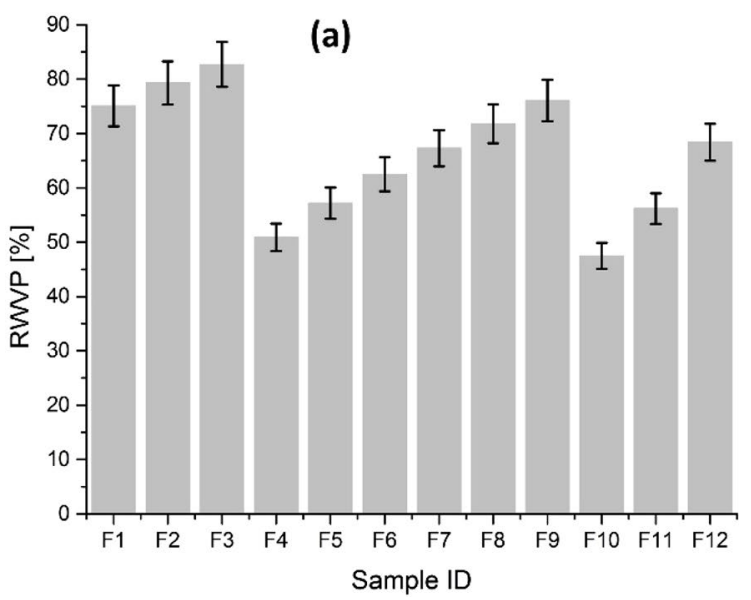

(b)

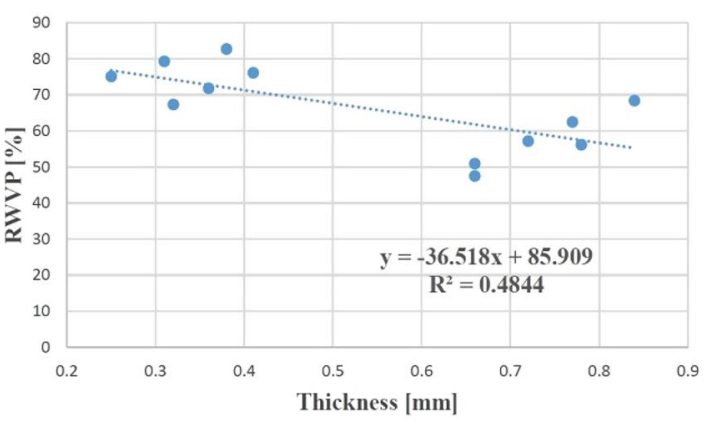

Figure 7. (a) Relative water vapour permeability of cotton samples $\left(\mathrm{F}_{1}-\mathrm{F}_{6}\right)$ and polyester samples $\left(\mathrm{F}_{7}-\mathrm{F}_{12}\right)$, and (b) relative water vapour permeability as a function of thickness.

Relative water vapour permeability (RWVP). The relative water vapour permeability is a non-standardized parameter that has a practical influence on overall thermophysiological comfort. The closer the value of RWVP of a substrate to 100 specifies more permeability or in other words, the substrate has excellent permeability. The results of RWVP are presented in Fig. 7a and the results explain that an augmentation in thickness reduced RWVP value for both fabrics. Moreover, an increase in mass per unit area of all samples leads a diminution in their respective RWVP value. However, a homogenous deposition of ZnO NPs with longer sonication time works as a carrier pathway for the transportation of water vapours that slightly enhanced RWVP for both type of substrates.

Figure 7b explains the overall results of RWVP as a function of thickness. The trendline shows a decreasing tendency of RWVP with an augmentation in thickness. The parameters of regression equation and the value of $\mathrm{R}^{2}$ coefficient statically explain the dependency of RWVP on material thickness. A negative linear relationship with a fair dependency trend was observed between thickness and RWVP performance of investigated samples. The obtained results are in agreement with the findings of Angelova et al. ${ }^{5}$.

Absolute evaporative resistance $\left(R_{e t}\right)$. Figure 8 shows the results of absolute evaporative resistance of all samples. The results depicted that an augmentation in fabric thickness enhances the evaporative resistance for observed samples. However, after the deposition of $\mathrm{ZnO}$ NPs via sonication method, a significant diminution was observed in absolute evaporative resistance (Fig. 8a). The obtained results further enlighten the benefits of sonication not only during the synthesis of novel materials but also for the augmentation of thermophysiological comfort.

Figure $8 \mathrm{~b}$ depicts that absolute evaporative resistance is a function of thickness and the trendline shows an increased tendency with the augmentation of thickness. Regression equation and $\mathrm{R}^{2}$ coefficient statically explain absolute evaporative resistance dependency on fabric thickness. A positive linear relationship and a dependency trend was observed between evaporative resistance and sample thickness. The observed results are in good agreement with the findings of Zhou et al. ${ }^{27}$. 


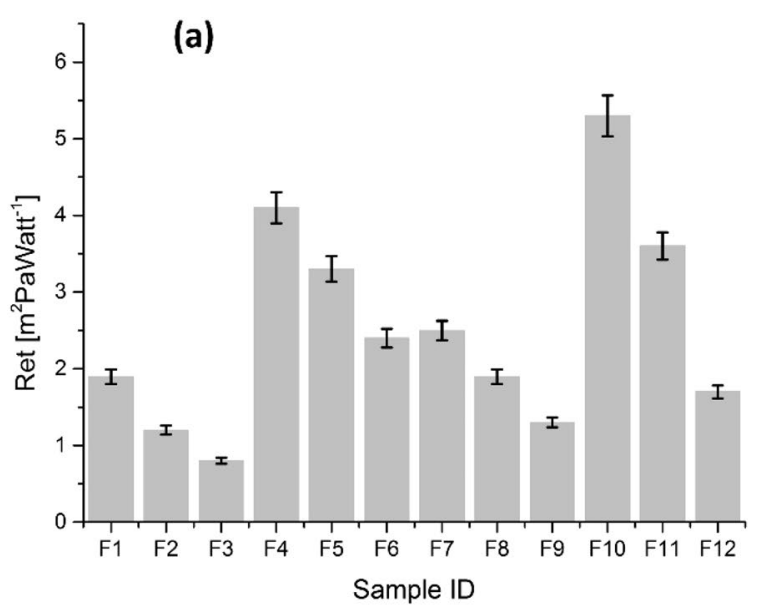

(b)

Figure 8. (a) Absolute evaporative resistance of cotton samples $\left(\mathrm{F}_{1}-\mathrm{F}_{6}\right)$ and polyester samples $\left(\mathrm{F}_{7}-\mathrm{F}_{12}\right)$, and (b) absolute evaporative resistance as a function of thickness.
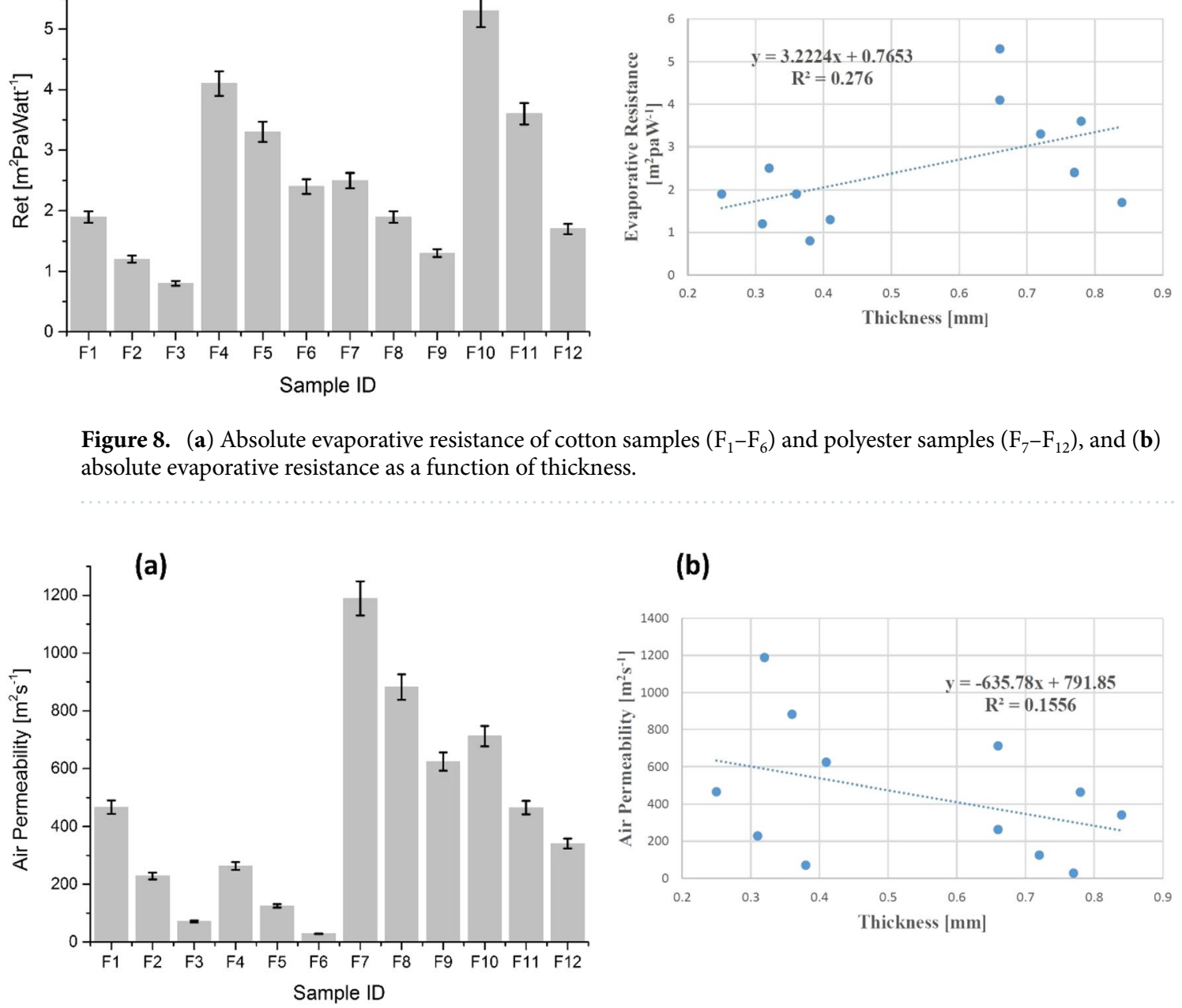

Figure 9. (a) Air permeability of cotton samples $\left(\mathrm{F}_{1}-\mathrm{F}_{6}\right)$ and polyester samples $\left(\mathrm{F}_{7}-\mathrm{F}_{12}\right)$, and (b) air permeability as a function of thickness.

Air permeability. Air permeability is another influential variable in order to evaluate thermophysiological comfort. This property performs an important role in moisture transportation from human body to external atmosphere. In principle, this property is based on pore size distribution by which air permeation takes place. Air permeability results are illustrated in Fig. 9a.

Air permeability values decreased significantly for all treated samples of cotton $\left(\mathrm{F}_{2}, \mathrm{~F}_{3}, \mathrm{~F}_{5}, \mathrm{~F}_{6}\right)$ and polyester $\left(\mathrm{F}_{8}, \mathrm{~F}_{9}, \mathrm{~F}_{11}, \mathrm{~F}_{12}\right)$ than untreated samples i.e. $\mathrm{F}_{1}, \mathrm{~F}_{4}$ for cotton and $\mathrm{F}_{7}, \mathrm{~F}_{10}$ for polyester. The results depicted that the deposition of $\mathrm{ZnO}$ NPs via sonication covers the portion of porosity by accumulating in void spaces and blocks the majority of pores. Additionally, ZnO NPs coating on fabrics induce difficulties in air pathway and results in the diminution of air permeability. These results are in good agreement with the findings of Shaid et al. ${ }^{8}$.

Figure $9 \mathrm{~b}$ shows the results of air permeability as a function of thickness and trendline depicts a decreasing tendency of air permeability with the augmentation of thickness. In addition, Regression equation and $\mathrm{R}^{2}$ coefficient statically explain dependency of air permeability on sample thickness. A negative linear relationship and a random distribution was observed between air permeability and thickness.

OMMC. The OMMC is another important parameter and influential indicator for thermophysiological comfort evaluation. OMMC describes the capacity of a textile substrate to transfer liquid in all three dimensions. The results of OMMC of all samples are illustrated in Fig. 10a. The OMMC values ranges from (0 to 1) whereas a value closer to 1 indicates better moisture management properties of a substrate. OMMC results were higher for all treated samples of cotton $\left(\mathrm{F}_{2}, \mathrm{~F}_{3}, \mathrm{~F}_{5}, \mathrm{~F}_{6}\right)$ and polyester $\left(\mathrm{F}_{8}, \mathrm{~F}_{9}, \mathrm{~F}_{11}, \mathrm{~F}_{12}\right)$ than untreated samples i.e. $\mathrm{F}_{1}, \mathrm{~F}_{4}$ for cotton and $\mathrm{F}_{7}, \mathrm{~F}_{10}$ for polyester. The results show that the deposition of $\mathrm{ZnO}$ NPs through sonication induced positive and significant effects on the moisture management properties. In a previous study, the advantages of using sonication as an economical, user friendly and robust tool during the synthesis of nanomaterials and functional textiles is explained in details ${ }^{28}$. Fluid flow acceleration occurs inside fibre internal structure during sonication, and textile substrate swelling is achieved by acoustic cavitation phenomenon. These two factors resulted in better moisture management properties ${ }^{29}$. OMMC results are in agreement with the findings of Mishra et al. ${ }^{6}$. 


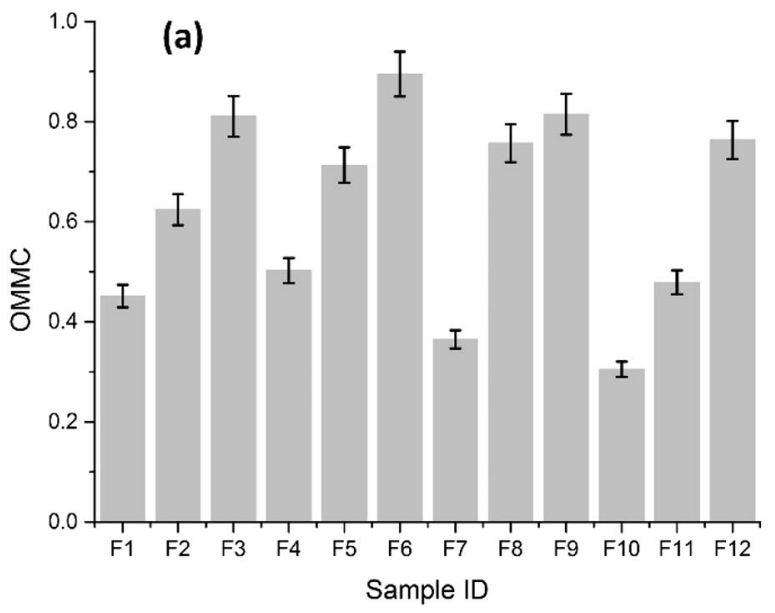

(b)

Figure 10. (a) The overall moisture management capacity of cotton samples $\left(\mathrm{F}_{1}-\mathrm{F}_{6}\right)$ and polyester samples $\left(\mathrm{F}_{7}-\right.$ $\mathrm{F}_{12}$ ), and (b) the overall moisture management capacity as a function of thickness.

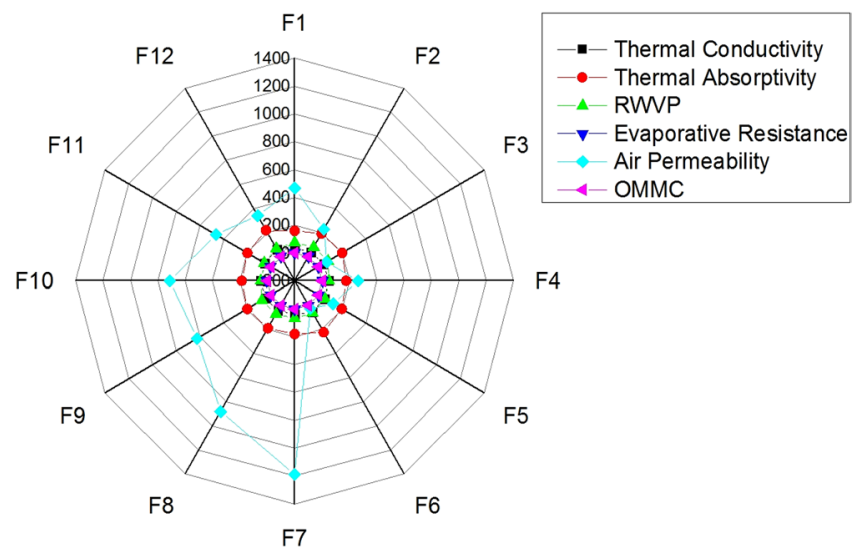

Figure 11. Spider plot of thermophysiological evaluation of used fabrics.

Figure 10b presents the results of OMMC as a function of thickness and the trendline reveals a slight increase in OMMC values with an augmentation in thickness. Moreover, Regression equation and $\mathrm{R}^{2}$ coefficient statically explain OMMC dependency on sample thickness. A positive linear relationship with relatively random distribution was observed between OMMC and thickness.

For a twinkling analysis of thermophysiological properties of investigated samples, a spider plot is drawn and shown in Fig. 11. The spider plot is based on original experimental values. The practical images of untreated samples and $\mathrm{ZnO}$ treated samples are provided in Fig. 12.

Washing stability (reusability). The durability of ZnO NPs deposited on cotton and polyester fabrics was evaluated against washing. In this typical method, total number of $\mathrm{Zn}^{2+}$ ions occurred in solution were taken as washing durability. Lower quantity of $\mathrm{Zn}^{2+}$ ions indicates higher durability. The total amount of $\mathrm{Zn}^{2+}$ ions appeared after 5th cycle was $37 \mathrm{ppm}, 74 \mathrm{ppm}, 45 \mathrm{ppm}, 38 \mathrm{ppm}, 64 \mathrm{ppm}$ and $57 \mathrm{ppm}$ for samples $\mathrm{F}_{2}, \mathrm{~F}_{3}, \mathrm{~F}_{6}, \mathrm{~F}_{8}$, $\mathrm{F}_{9}$ and $\mathrm{F}_{12}$ respectively. The observed results are significantly positive and depicts that only $6 \% \mathrm{ZnO}$ NPs were removed on average from treated samples after 5 th cycle whereas sample by sample percentage was $6.3 \%$ for $\mathrm{F}_{2}$, $6.7 \%$ for $\mathrm{F}_{3}, 4.0 \%$ for $\mathrm{F}_{6}, 7.7 \%$ for $\mathrm{F}_{8}, 6.2 \%$ for $\mathrm{F}_{9}$ and $5.2 \%$ for $\mathrm{F}_{12}$ respectively. The reusability results show that $\mathrm{ZnO}$ NPs synthesized by sonication were attached adhesively to fabric as their minimal quantity was removed after five consecutive cycles as illustrated in Fig. 13. This confirmed the stability and reusability of synthesized samples.

Pore size distribution. BET (Brunauer, Emmet and Teller) analysis was performed to estimate pore size distribution and specific surface area. These microstructural properties are highly influential and significantly depends on porosity, geometry and morphology of $\mathrm{ZnO}$ NPs. These parameters were determined under $\mathrm{N}_{2}$ $\left(-196^{\circ} \mathrm{C}\right)$ atmosphere. The adsorbed volume of gas on surface of textile substrate was considered as total area including specific surface area and pore size distribution. The representation of experimental conditions and the results of particle size, pore volume, surface area and pore size distribution are reported in Table 3. 


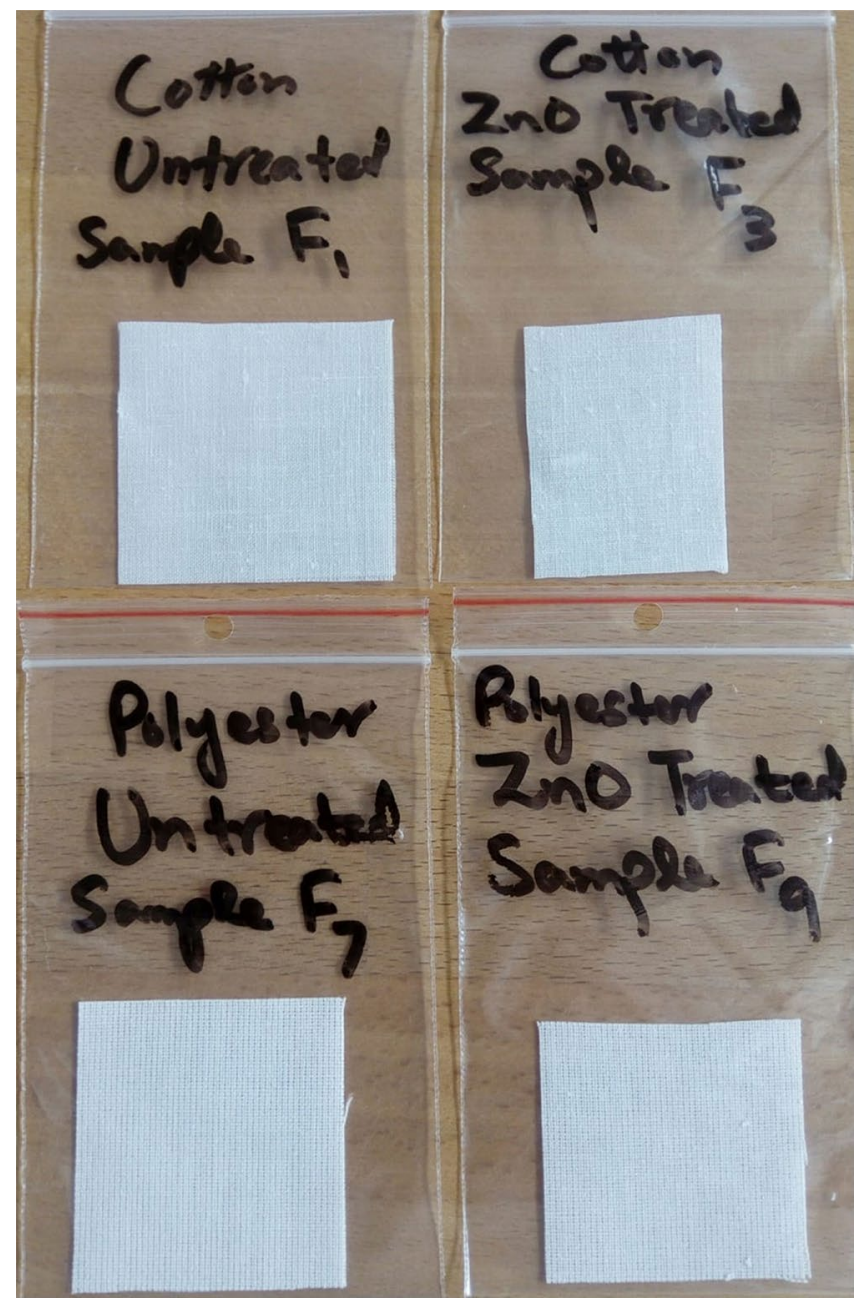

Figure 12. The practical images of untreated cotton and polyester fabrics and $\mathrm{ZnO}$ coated cotton and polyester fabrics respectively.

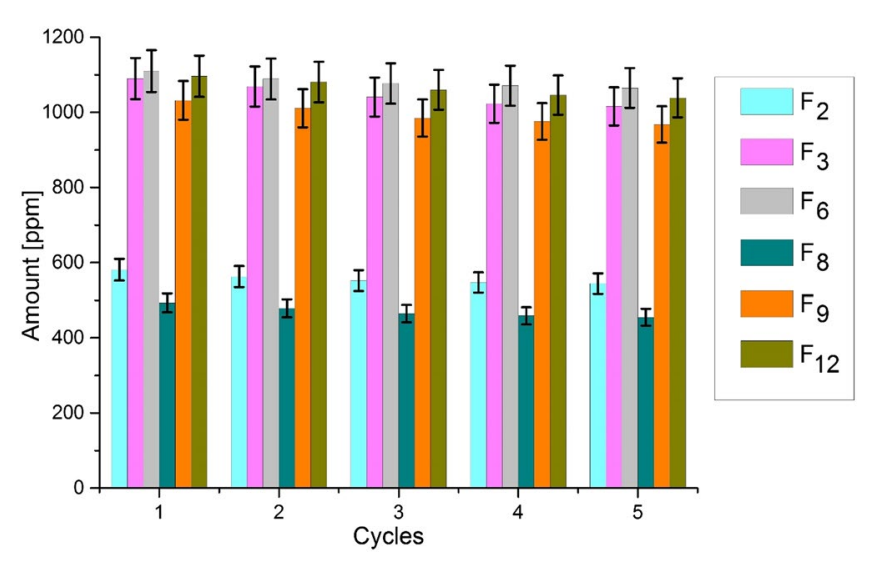

Figure 13. Reusability and washing stability of different samples.

\section{Conclusion}

The motivation of this work was to evaluate comfort properties of $\mathrm{ZnO}$ NPs coated fabrics with varying thickness. The following conclusions were drawn that significantly based on heat and moisture transportation and air permeability. 


\begin{tabular}{|c|c|c|c|c|c|}
\hline Sample ID & Sonication time (min) & $\mathrm{ZnO}$ particle size $(\mathrm{nm})$ & Surface area $\left(\mathrm{m}^{2} \mathrm{~g}^{-1}\right)$ & Pore volume $\left(\mathrm{cm}^{3} \mathrm{~g}^{-1}\right)$ & Pore size $(\mathbf{n m})$ \\
\hline $\mathrm{F}_{1}$ & - & - & - & - & - \\
\hline $\mathrm{F}_{2}$ & 60 & 31.6 & 104 & 0.31 & 22 \\
\hline $\mathrm{F}_{3}$ & 60 & 28.3 & 113 & 0.27 & 26 \\
\hline $\mathrm{F}_{4}$ & - & - & - & - & - \\
\hline $\mathrm{F}_{5}$ & 60 & 30.1 & 101 & 0.26 & 21 \\
\hline $\mathrm{F}_{6}$ & 60 & 28.4 & 109 & 0.22 & 24 \\
\hline $\mathrm{F}_{7}$ & - & - & - & - & - \\
\hline $\mathrm{F}_{8}$ & 60 & 32.8 & 110 & 0.28 & 23 \\
\hline $\mathrm{F}_{9}$ & 60 & 29.2 & 112 & 0.25 & 27 \\
\hline $\mathrm{F}_{10}$ & - & - & - & - & - \\
\hline $\mathrm{F}_{11}$ & 60 & 33.1 & 101 & 0.24 & 30 \\
\hline $\mathrm{F}_{12}$ & 60 & 31.5 & 104 & 0.22 & 32 \\
\hline
\end{tabular}

Table 3. Experimental detail and results of BET analysis of all samples.

- Fabric thickness is an effective variable that affects comfort properties particularly thermal conductivity and thermal absorptivity. Furthermore, the results between thermal conductivity and thickness were statistically significant with $\mathrm{R}^{2}$ value 0.9125 . By keeping comfort feeling in mind, the result illustrated that the deposition of $\mathrm{ZnO}$ NPs by sonication improved thermal conductivity significantly. Additionally, the values of thermal conductivity of polyester were higher than cotton in a parallel comparison of thickness.

- Consistent results were found for thermal absorptivity of untreated and treated samples. Fabric thickness played a metaphorical role for thermal absorptivity. For thermal absorptivity, the results of regression analysis showed that the value of $\mathrm{R}^{2}$ is a little bit lower as an abnormal distribution was observed. Moreover, the results showed that $\mathrm{ZnO}$ NPs coating on fabrics by sonication improved thermal absorptivity to some extent.

- Structure and morphology of textile materials play a major role in the evaluation of fabric comfort. Moisture transportation phenomenon significantly depends on porosity. Relative water vapor permeability results were decreased for both cotton and polyester as fabric thickness and quantity of $\mathrm{ZnO}$ NPs increased. This decrease was due to lower porosity.

- Absolute evaporative resistance was increased as thickness and amount of $\mathrm{ZnO}$ NPs increased. However, a diminution for absolute evaporative resistance results was observed after $\mathrm{ZnO}$ NPs coating on fabrics by sonication. The lateral was sonication impact as ultrasonic energy untie fibre structure and allow fluid to pass through.

- Besides the inspirational findings, many influential variables of heat and moisture transportation i.e. thermal diffusivity, thermal resistance, heat flux, wetting, accumulative one-way transport index etc. still need to investigate because comfort properties could depend on them also. Therefore, for more deeper comfort zone, these variables will be investigated.

Received: 22 April 2020; Accepted: 6 November 2020

Published online: 03 December 2020

\section{References}

1. Chen, Q., Tang, K.-P.M., Ma, P., Jiang, G. \& Xu, C. Thermophysiological comfort properties of polyester weft-knitted fabrics for sports T-shirt. J. Text. Inst. 108, 1421-1429 (2017).

2. Mansoor, T., Hes, L., Bajzik, V. \& Noman, M. T. Novel method on thermal resistance prediction and thermo-physiological comfort of socks in wet state. Text. Res. J. 90, 1-20. https://doi.org/10.1177/0040517520902540 (2020).

3. Öner, E. \& Okur, A. Thermophysiological comfort properties of selected knitted fabrics and design of T-shirts. J. Text. Inst. 106, 1403-1414 (2015).

4. Azeem, M. et al. Comfort properties of nano-filament polyester fabrics: thermo-physiological evaluation. Ind. Tex. 69, 315-321 (2018).

5. Angelova, R. A. et al. Heat and mass transfer through outerwear clothing for protection from cold: influence of geometrical, structural and mass characteristics of the textile layers. Text. Res. J 87, 1060-1070 (2017).

6. Mishra, R., Veerakumar, A. \& Militky, J. Thermo-physiological properties of 3D spacer knitted fabrics. Int. J. Cloth. Sci. Tech. 28, $328-339$ (2016).

7. Gunasekaran, G., Prakash, C. \& Periyasamy, S. Effect of charcoal particles on thermophysiological comfort properties of woven fabrics. J. Nat. Fib. 1, 1-14 (2019).

8. Shaid, A., Fergusson, M. \& Wang, L. Thermophysiological comfort analysis of aerogel nanoparticle incorporated fabric for fire fighter's protective clothing. Chem. Mat. Eng. 2, 37-43 (2014).

9. Noman, M. T. \& Petru, M. Effect of sonication and nano $\mathrm{TiO}_{2}$ on thermophysiological comfort properties of woven fabrics. ACS Omega 5, 11481-11490 (2020).

10. Noman, M. T., Petru, M., Amor, N., Yang, T. \& Mansoor, T. Thermophysiological comfort of sonochemically synthesized nano TiO 2 coated woven fabrics. Sci. Rep. 10, 1-12 (2020).

11. Gao, N. \& Fang, X. Synthesis and development of graphene-inorganic semiconductor nanocomposites. Chem. Rev. 115, 8294-8343 (2015).

12. Kwon, S.-N., Yu, J.-H. \& Na, S.-I. A systematic approach to $\mathrm{ZnO}$ nanoparticle-assisted electron transport bilayer for high efficiency and stable perovskite solar cells. J. Alloys Compd. 801, 277-284 (2019). 
13. Shkir, M., Hamdy, M. S. \& AlFaify, S. A facile one pot flash combustion synthesis of ZnO nanoparticles and their characterizations for photocatalytic applications. J. Mol. Struct. 1197, 610-616 (2019).

14. Taylor, C. M., Ramirez-Canon, A., Wenk, J. \& Mattia, D. Enhancing the photo-corrosion resistance of ZnO nanowire photocatalysts. J. Hazard. Mater. 378, 120799 (2019).

15. Gerbreders, V. et al. Hydrothermal synthesis of $\mathrm{ZnO}$ nanostructures with controllable morphology change. Cryst. Eng. Comm. 22, $1346-1358(2020)$

16. Khan, M. F. et al. Sol-gel synthesis of thorn-like $\mathrm{ZnO}$ nanoparticles endorsing mechanical stirring effect and their antimicrobial activities: potential role as nano-antibiotics. Sci. Rep. 6, 27689 (2016).

17. Müller, R. et al. Chemical vapor deposition growth of zinc oxide on sapphire with methane: initial crystal formation process. Cryst. Growth Des. 19, 4964-4969 (2019).

18. Khan, H. R. et al. electronic tuning of Zinc oxide by Direct fabrication of chromium (cr) incorporated photoanodes for Visiblelight driven water splitting applications. Sci. Rep. 10, 1-10 (2020).

19. Laurenti, M., Garino, N., Porro, S., Fontana, M. \& Gerbaldi, C. Zinc oxide nanostructures by chemical vapour deposition as anodes for Li-ion batteries. J. Alloys Compd. 640, 321-326 (2015).

20. Noman, M. T. \& Petru, M. Functional properties of sonochemically synthesized zinc oxide nanoparticles and cotton composites. Nanomaterials 10, 1661. https://doi.org/10.3390/nano10091661 (2020).

21. Noman, M. T., Ashraf, M. A. \& Ali, A. Synthesis and applications of nano-TiO ${ }_{2}$ : a review. Environ. Sci. Pollut. Res. 26, 3262-3291 (2019).

22. Noman, M. T. et al. In-situ development of highly photocatalytic multifunctional nanocomposites by ultrasonic acoustic method. Ultrason. Sonochem. 40, 41-56 (2018).

23. Dal, V., Şimşek, R., Hes, L., Akçagün, E. \& Yilmaz, A. Investigation of thermal comfort properties of zinc oxide coated woven cotton fabric. J. Text. Inst. 108, 337-340 (2017).

24. Noman, M. T., Petru, M., Militký, J., Azeem, M. \& Ashraf, M. A. One-pot sonochemical synthesis of ZnO nanoparticles for photocatalytic applications modelling and optimization. Mater. 13, 14. https://doi.org/10.3390/ma13010014 (2020).

25. Dalbaşi, E. S. \& Özçelik Kayseri, G. A research on the comfort properties of linen fabrics subjected to various finishing treatments. J. Nat. Fib. 1, 1-14 (2019).

26. Arumugam, V., Mishra, R., Militky, J., Davies, L. \& Slater, S. Thermal and water vapor transmission through porous warp knitted 3D spacer fabrics for car upholstery applications. J. Text. Inst. 109, 345-357 (2018).

27. Zhou, R., Wang, X., Yu, J., Wei, Z. \& Gao, Y. Evaluation of luster, hand feel and comfort properties of modified polyester woven fabrics. J. Eng. Fib. Fabr. 12, 70-77 (2017).

28. Noman, M. T. et al. Sonochemical synthesis of highly crystalline photocatalyst for industrial applications. Ultrason. 83, 203-213 (2018).

29. Noman, M. T., Ashraf, M. A., Jamshaid, H. \& Ali, A. A novel green stabilization of $\mathrm{TiO}_{2}$ nanoparticles onto cotton. Fib. Polym. 19, 2268-2277 (2018).

\section{Acknowledgements}

This work was supported by the Ministry of Education, Youth and Sports of the Czech Republic and the European Union (European Structural and Investment Funds-Operational Programme Research, Development and Education) in the frames of the project "Modular platform for autonomous chassis of specialized electric vehicles for freight and equipment transportation", Reg. No. CZ.02.1.01/0.0/0.0/16_025/0007293. The results of the project "Thermal nano insulation for automotive, aviation and aeronautics", registration number TH04020189 were obtained through the financial support of Technology Agency of the Czech Republic within the Epsilon Program. This publication was supported by Institutional Endowment for the Long-Term Conceptual Development of Research Institutes, as provided by the Ministry of Education, Youth and Sports of the Czech Republic in the year 2019.

\section{Author contributions}

M.T.N. conceived, designed, performed experiments and wrote manuscript. M.P. analysed the results, supervised and acquired funding. N.A. performed experiments and analysed the results. P.L. performed experiments and proofread the manuscript. All of the authors participated in critical analysis and preparation of the manuscript. All authors have read and agreed to the published version of the manuscript.

\section{Competing interests}

The authors declare no competing interests.

\section{Additional information}

Correspondence and requests for materials should be addressed to M.T.N.

Reprints and permissions information is available at www.nature.com/reprints.

Publisher's note Springer Nature remains neutral with regard to jurisdictional claims in published maps and institutional affiliations.

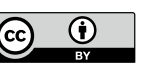

Open Access This article is licensed under a Creative Commons Attribution 4.0 International License, which permits use, sharing, adaptation, distribution and reproduction in any medium or format, as long as you give appropriate credit to the original author(s) and the source, provide a link to the Creative Commons licence, and indicate if changes were made. The images or other third party material in this article are included in the article's Creative Commons licence, unless indicated otherwise in a credit line to the material. If material is not included in the article's Creative Commons licence and your intended use is not permitted by statutory regulation or exceeds the permitted use, you will need to obtain permission directly from the copyright holder. To view a copy of this licence, visit http://creativecommons.org/licenses/by/4.0/.

(C) The Author(s) 2020 